\title{
Cristo Epistêmico
}

\section{Elisa Larkin Nascimento ${ }^{1}$}

IPEAFRO, Rio de Janeiro, Brasil

E-mail: pesquisa@ipeafro.org.br 


\section{Resumo}

Guerreiro Ramos exerceu sua "sociologia militante" no Teatro Experimental do Negro. Desde jovem, ele vinha elaborando sua ideia do "sujeito epistêmico". Seu legado teórico dialoga com o pensamento sociológico contemporâneo internacional. A autora propõe uma leitura de Guerreiro Ramos em diálogo com autores como Agnes Heller, W. E. B. Du Bois e Manuel Castells, enfocando paradigmas como redução sociológica, vida cotidiana, carecimentos radicais, identidades de resistência e de projeto. Neste artigo examina-se o papel de Guerreiro Ramos na idealização do Concurso Cristo de Cor, iniciativa do Teatro Experimental do Negro em 1955, realçando o TEN como exemplo do "sujeito epistêmico". São aprecia textos de Guerreiro Ramos sobre a pintura de Abdias Nascimento, escritos durante o período de exílio dos dois nos EUA, concluindo que a abordagem da estética negra nesse período dá continuidade ao enfoque sobre esse tema desenvolvido nos trabalhos anteriores de Guerreiro Ramos no TEN.

Palavras-chave: Sociologia Brasileira. Negros - Brasil. Pensamento Pós-moderno. Arte Negra. Movimento Negro.

\section{Abstract}

Guerreiro Ramos practiced his "militant sociology" in the Black Experimental Theater (TEN). As a young man, he had already been refining his idea of the "epistemic actor". His theoretical legacy converses with contemporary international sociology. The author proposes a reading of Guerreiro Ramos in dialogue with authors like W. E. B. Du Bois, Agnes Heller, and Manuel Castells, focusing on paradigms like sociological reduction, everyday life, radical privations, identities of resistance and project. She examines Guerreiro Ramos's role as idealizer of the TEN's Arts Contest on the theme of the Black Christ (1955), emphasizing TEN's role as an "epistemic actor". She looks at Ramos's texts on the painting of Abdias Nascimento, written during their period of exile in the USA, understanding his approach to black aesthetics in this period as a continuum with his treatment of this theme in his earlier work with TEN.

Keywords: Brazilian Sociology. Blacks in Brazil. Post-Modern Thought. Black Art. Black Movements. 


\section{Introdução}

Seminário "Guerreiro Ramos, Intérprete do Brasil", organizado pelo Núcleo de Estudos de Identidade e Relações Interétnicas (NUER), da Universidade Federal de Santa Catarina, promoveu um momento único de reflexão sobre a vida e obra desse humanista brasileiro. Pela envergadura e sensibilidade do homenageado, tal exercício significa considerarmos a história do pensamento cr[itico no país. A contribuição do professor Raul Antelo, que abriu o seminário mostrando um Guerreiro Ramos "não-contemporizador" ao traçar o desenvolvimento de suas ideias desde jovem, confirma a grandeza e originalidade desse pensador "[...] muito singular da cultura como um todo e do pensamento nacional, em particular." (Antelo, 2015, p. 1).

Epígrafe do ensaio, a frase do jovem Guerreiro "Sou rebelde porque humano" ecoaria bem mais tarde - quase quatro décadas após a sua enunciação em artigo de 1937 - nos trabalhos de um seminário realizado pelo Centro das Humanidades da Universidade Wesleyan, nos Estados Unidos, em 1969-70, sobre o tema "A Humanidade em Revolta". Com duração de um ano, o seminário reuniu destacados intelectuais e artistas como Herbert Marcuse, Buckminster Fuller, Norman O. Brown, Leslie Fiedler, John Cage e outros. Guerreiro não participou diretamente, mas seu testemunho sobre a obra artística do colega e amigo Abdias Nascimento, então professor e Fellow da Wesleyan - este, sim, participante do seminário - se insere perfeitamente no objetivo do certame. A exposição das pinturas de Abdias, atividade cultural complementar ao seminário, se abrigou na Casa Malcolm X, centro cultural daquela prestigiosa instituição acadêmica (Nascimento, A., 1969). 


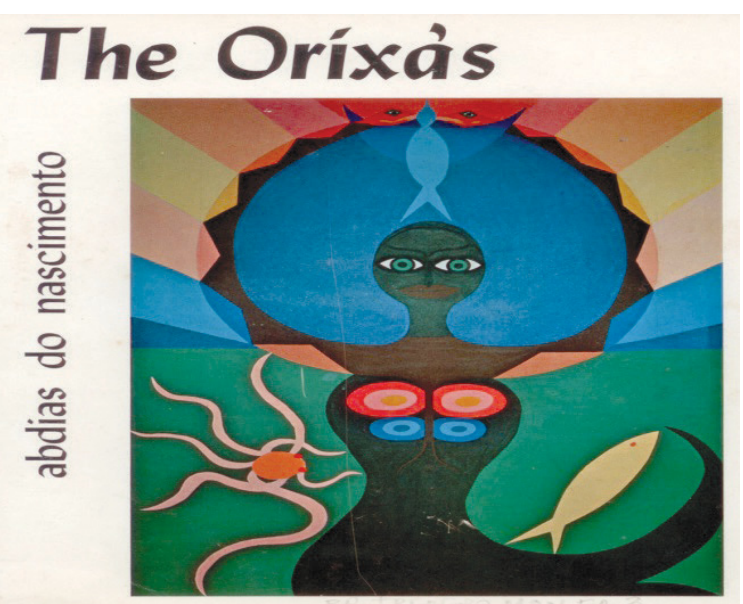

Foto 1: Capa do catálogo, exposição de Abdias Nascimento, Malcolm X House (Middletown, CN, EUA: Center for the Humanities, Wesleyan University, 1969)

Fonte: IPEAFRO (1956)

Criador do Teatro Experimental do Negro (TEN) em 1944, Abdias havia recebido o rebelde Guerreiro no TEN por volta de 1947, depois da comemoração do segundo aniversário de sua fundação. Ali o sociólogo desenvolveu, entre outras atividades, seu trabalho de sociodrama inspirado no psicodrama de Jacob Levy Moreno (Guerreiro Ramos, 1950a, 1950b). Além disso, Abdias e Guerreiro participaram juntos dos trabalhos do Instituto Superior de Estudos Brasileiros (ISEB), do qual Abdias foi o primeiro diplomado (IPEAFRO, 1956).

Guerreiro Ramos cita sua participação no TEN como práxis que fundamentou o desenvolvimento de sua abordagem sociológica (Guerreiro Ramos, 1995, p. 260). Ao arregaçar as mangas e mergulhar no ativismo cultural, sociorracial e intelectual do TEN, Guerreiro vivia a "ação do intelectual novo" que ele cedo preconizara: “[...] ao jovem novo, incumbe o papel de afirmar-se, de comprometer-se no que diz e no que escreve" (Guerreiro Ramos, 1937). Mais tarde, ele identificou o TEN como a mais destacada manifestação da nova fase dos estudos das relações raciais no Brasil, “[...] caracterizada pelo fato de que, no presente, o negro se recusa a servir de mero tema de dissertações 'antropológicas', e passa a agir no sentido de desmascarar os preconceitos de cor" (Guerreiro Ramos, 1995, p. 205). Ou seja, o TEN incorporava exemplo vivo do "sujeito epistêmico" cuja categoria o jovem Guerreiro 
começara a elaborar desde cedo (Antelo, 2015, p. 5). A crônica desse exemplo não cabe no presente trabalho, mas certamente constatará o fato quem estudar a história, as iniciativas e as atividades do TEN, algo que já tive a honra e oportunidade de ensaiar (Nascimento, E., 2003, p. 245-380).

O legado sociológico de Guerreiro Ramos extrapola o contexto brasileiro, compondo um elo matricial no encadeamento da "rica tradição do pensamento crítico que une o ubíquo ao utópico, o local ao global", conforme Clóvis Brigagão (1995, p. 11). No intuito de contribuir para o diálogo promovido pelo NUER, pretende-se aqui tecer algumas considerações sobre o pensamento e a atuação de Guerreiro Ramos, relembrando, de início, uma leitura dialógica de sua obra e a da filósofa húngara Agnes Heller e os sociólogos W. E. B. Du Bois e Manuel Castells que ajuda a pontuar implicações da noção e ação do "sujeito epistêmico" em nível mundial. Também me refiro a uma instância da atuação de Guerreiro Ramos no TEN: a proposta e realização do Concurso de Artes Plásticas sobre o Tema do Cristo Negro em 1955. Ele retoma o tema da estética negra mais tarde, no período de exílio nos Estados Unidos, em seus ensaios críticos sobre a pintura de Adias Nascimento.

\section{Diálogo Dialético}

Tanto no plano brasileiro como no internacional, a obra de Guerreiro Ramos contribuiu para as "revisões e rearticulações dos mapas cognitivos" que seu tempo exigia (Brigagão, 1995, p. 11) ao criar categorias e paradigmas como a redução sociológica, a teoria da vida humana associativa, a postura parentética do homem em relação às organizações e a globalidade dos recursos e dos sistemas econômicos e ecológicos. Seu singular enfoque sobre a questão racial apontava caminhos para a ciência e a transformação social, antecipando discussões e propostas políticas hoje relevantes. Nesse particular, a visão de Guerreiro coincide com aquela do sociólogo negro norte-americano W. E. B. Du Bois (1868-1963), quando anunciou em 1903 que “o problema do século XX será o problema da linha de cor" (Du Bois, 1980, p. 372). Pensador e ativista pan-africano, Du Bois figura entre os 
intelectuais que mais contribuíram para a sociologia e a transformação social naquele século.

A filósofa húngara Agnes Heller (1929), discípula de Lukács, desenvolve desde dentro uma critica ao pensamento marxista a partir de problemas postos pelos rumos da sociedade moderna e pós-moderna, trabalho que a levou também a construir paradigmas e instrumentos analíticos e conceituais como os da vida cotidiana, carecimentos radicais, microanálise social e objetivações em si mesmas (Heller, 1982 ; 1987). Seu pensamento dialoga de forma instigante com o de Guerreiro Ramos. Sua crítica à tese segundo a qual as leis econômicas do desenvolvimento das forças produtivas da sociedade capitalista conduzem necessariamente à revolução e à construção da sociedade sem classes, por exemplo, lembra Guerreiro Ramos (1995, p. 261), quando afirma, em entrevista dada ao jornal carioca Última Hora em 1956, que a ciência social do século XX

[...] (a) não admite o primado sistemático de nenhum critério operatório de dialetização, nem tampouco se admite como um monismo determinista dialético; (b) não admite a conclusão do processo histórico-dialético, nem sabe de antemão aonde conduz este processo; (c) dialetiza as relações entre a teoria e a prática.

Assim como Guerreiro, Agnes Heller propõe ampliar o enfoque sobre a realidade social, introduzindo como de significação primária atividades e fatos próprios a diversas esferas. A primazia do enfoque econômico cede lugar à centralidade de fenômenos como linguagem e estética, em alguns casos até "[...] negligenciando mesmo os seus aspectos econômicos. O que nos interessa aqui é focalizar a questão do ângulo psicológico, enquanto socialmente condicionado" (Guerreiro Ramos, 1995, p. 196-197). Os dois autores buscam aquilo que Guerreiro queria no seu conceito ampliado de redução sociológica: uma “[...] leitura inteligente do real em suas múltiplas expressões" (Guerreiro Ramos, 1996, p. 11).

Num ensaio sobre a hermenêutica nas ciências sociais, Agnes Heller fala da "prisão da contemporaneidade" em que se encontra o homem moderno após o iluminismo: o paradoxo de buscar um "verdadeiro conhecimento do mundo" quando se reconhece esse 
conhecimento limitado por situar-se dentro de seu tempo e de seu espaço (Heller, 1989, p. 291). Para superar esse paradoxo, seria preciso encontrar um "ponto de Arquimedes" fora desse tempo e espaço, o que permitiria ver nitidamente a sua natureza. Heller (1989, p. 292) propõe o seguinte:

Suponhamos que sejamos capazes de conversar com os atores de épocas passadas ou com membros de culturas alheias; suponhamos ainda que possamos ler a mente desses povos (ou seus textos) e vir a saber o que realmente significavam (ou significam). Finalmente, vamos supor que devido a tudo isso podemos nos olhar de volta a nós mesmos, com esses próprios olhos alheios, desde o contexto cultural desse "outro". Se pudéssemos fazer esses "outros" levantar as suas questões, e avaliar e julgar nossa história e nossas instituições desde a sua perspectiva, em outras palavras sua consciência histórica, teremos estabelecido um ponto de Arquimedes fora de nossa própria cultura.

W. E. B. Du Bois e Guerreiro Ramos estão entre os atores autorais de um processo parecido, ocorrido ao longo do século XX e que continua no presente. Os olhares "de fora" articulam suas críticas às posturas e teorias ocidentais, influenciando profundamente a sua evolução, quando não as substituindo por outras propostas teóricas próprias às suas experiências específicas. Grande parte dessa literatura enfoca “o problema da linha de cor", conforme previa Du Bois. A literatura é vasta e inclui autores como Cheikh Anta Diop, fundador do Instituto Fundamental da África Negra, que rebateu as teses da inferioridade africana e iniciou uma nova tradição e novos paradigmas de pesquisa (Diop, 1955; 1959).

Assim, a ideia do ponto de Arquimedes chama a atenção para o mesmo fenômeno que constitui o objeto motivador da redução sociológica proposta por Guerreiro Ramos: o questionamento crítico do olhar ocidental imposto como mediador universal de uma realidade humana tida como globalmente uniforme em acordo com o modelo europeu.

Consideremos de início, a noção de centro. O eurocentrismo traduz a acepção weberiana de centro como região ou localidade desde a qual um grupo dominante faz incidir sobre o restante da coletividade 
os padrões dominantes por ele definidos (Guerreiro Ramos, 1995, p. 65). No contexto de teorias contemporâneas como a afrocentricidade, o centro se refere ao ponto de vista ou localização do sujeito: desde que posição ele observa, analisa e compreende o mundo (Asante, 2009). O conceito antropológico de etnocentrismo, por sua vez, generaliza a tendência de cada grupo étnico a elaborar seu centro e valorizar sua própria cultura. Há uma tendência, alimentada por essa etimologia, de se fazer equivaler o eurocentrismo a um etnocentrismo específico. Sendo o etnocentrismo um fenômeno universal, atributo tanto dos europeus quanto dos nativos dos territórios colonizados, os europeus, ao exercê-lo, estariam agindo como todos os seres humanos, inclusive os próprios colonizados.

O primeiro equívoco desse raciocínio está no fato de que o eurocentrismo não corresponde a uma etnia, já que existem inúmeros grupos étnicos europeus; a ideologia eurocentrista abstrai as etnicidades e cultiva referências das civilizações grega e romana. Mais grave, entretanto, é a minimização do eurocentrismo como sistema de dominação. Sua identificação como "mais um etnocentrismo" o isenta de suas implicações nos processos de subjugação e de falsificação histórica, utilizados para impor um "etnocentrismo" específico como universal a todos os povos. O aparato bélico repressivo do sistema colonialista constitui exemplo extremo dessa violência, perpetrada e complementada por formas violentas mais sutis de natureza psicológica, estética, emotiva e intelectual. Guerreiro Ramos (1995) e Abdias Nascimento (2002) apontavam esse fenômeno ao lado de contemporâneos como Aimé Césaire (1955), Albert Memmi (1967); Frantz Fanon (1979, 1983), W. E. B. Du Bois (1986) e tantos outros.

Essa análise das múltiplas facetas do sistema de dominação colonial e a construção de métodos e propostas para sua superação marcaram de forma fundamental a evolução do pensamento e das formas sociais dos séculos XX-XXI. Vozes e atores sociais articularam seus "olhares de fora", um "ponto de Arquimedes" para a sociedade ocidental.

Ao pensar em provocar a produção de tais expressões, como se não já existissem, o subjuntivo de Agnes Heller (1989, p. 292: “se pudéssemos fazer esses 'outros' levantarem as suas questões") não deixa 
de apontar a relativa invisibilidade dessa literatura, a ponto de teóricos da sociedade ocidental deixar de tomar conhecimento da mesma ou, no máximo, atribuir-lhe reduzida importância.

Mesmo assim, além de assinalar o valor deste fenômeno para as ciências sociais, Heller estabelece pontes com os porta-vozes do "olhar de fora". Suas críticas à construção filosófica do proletariado como sujeito da revolução e à manipulação do destinatário da teoria (Heller, 1982, p. 13-14; Heller, 1989, p. 297) coincidem com a insistência de Guerreiro Ramos (1995; 1996) sobre a relação dialética entre prática e teoria e a necessidade de induzir a teoria sociológica a partir dos fatos concretos de uma realidade específica. Para Guerreiro Ramos, a prática de uma "sociologia militante" permite ao cientista instruir-se a partir da observação engajada ou do engajamento direto na ação do "destinatário" de sua teoria enquanto protagonista e não objeto da elaboração teórica. Assim ele explica vários momentos de sua participação no Teatro Experimental do Negro (TEN) (Guerreiro Ramos, 1995, p. 57, 205-209, 249-251, 260-261) e resume (Guerreiro Ramos, 1995, p. 260-261):

O Teatro Experimental do Negro me possibilitou a práxis do 'problema' e depois dela é que cheguei à teoria. O mesmo aconteceu com os meus estudos sobre mortalidade infantil e sobre problemas administrativos, econômicos e políticos do país. Quem não age, quem não participa do processo societário não compreende a sociedade.

Aliás, essa prática engajada está no cerne de sua metodologia indutiva, pois afirma (Guerreiro Ramos, 1995, p. 52) que “[...] a indução dos critérios de pensamento a partir da realidade é trabalho coletivo e não uma façanha individual, fruto de 'inspiração'".

Aqui surge o "sujeito epistêmico", o ator coletivo que levanta questões e demandas em direção à transformação social. Novamente a ideia dialoga com Agnes Heller, desta vez a sua teoria dos carecimentos radicais, necessidades ou anseios nascidos “[...] em consequência do desenvolvimento da sociedade civil, mas que não podem ser satisfeitos dentro dos limites dessa sociedade" (Heller, 1982, p. 133). Todo grupo social que expressa carecimentos radicais pode tornar-se sujeito 
da transformação revolucionária (Heller, 1982, p. 133). Ao articular o condicionamento específico dos segmentos sociais portadores dos carecimentos radicais, no intuito de desenvolver respostas eficazes para sua solução, os atores sociais transformam o carecimento como "ausência" em carecimento como "projeto" (Heller, 1982, p. 137). Num movimento análogo àquele dos olhares sobre a teoria das ciências sociais, ao darem voz às suas visões próprias da sociedade civil, desde a perspectiva de sua vivência do cotidiano e das estruturas sociais, eles possibilitam a formulação de estratégias de ação social e de políticas sociais relevantes aos seus carecimentos radicais.

É esse o procedimento de Guerreiro Ramos e do TEN ao analisar e agir diante do "problema do negro" no Brasil. Sua crítica do tratamento convencionalmente dispensado ao tema se conclui assim (Guerreiro Ramos, 1995, p. 236):

[...] o que se tem chamado no Brasil de "problema do negro" é reflexo da patologia social do "branco brasileiro, de sua dependência psicológica. Foi uma minoria de "brancos" letrados que criou esse "problema", adotando critérios de trabalho intelectual não induzidos de suas circunstâncias naturais diretas. Nestas condições, reconhece-se hoje a necessidade de reexaminar o tema das relações de raça no Brasil, dentro de uma posição de autenticidade étnica.

Quanto ao método formulado para a compreensão do problema nas suas verdadeiras dimensões, o autor indaga (Guerreiro Ramos, 1995, p. 198-199):

Qual será a situação vital a partir de que seria melhor propiciada para o estudioso a compreensão objetiva do tema em tela? Ao autor, parece aquela da qual o homem de pele escura seja, ele próprio, um ingrediente, contanto que este sujeito se afirme de modo autêntico como negro. Quero dizer, começa-se a melhor compreender o problema quando se parte da afirmação - níger sum. Esta experiência do níger sum, inicialmente, é, pelo seu significado dialético, na conjuntura brasileira em que todos querem ser brancos, um procedimento de alta rentabilidade científica, pois introduz o investigador em perspectiva que o habilita a ver nuanças que, de outro modo, passariam despercebidas. 
O Teatro Experimental do Negro tinha essa postura como centro de sua análise e ação social. Além de realizar apresentações teatrais, eventos culturais e encontros voltados à pesquisa, discussão e atuação política de combate ao racismo, o TEN registrava suas ideias e iniciativas em publicações capazes de difundir suas ideias e propostas (Nascimento, A., 1961, 1966, 1968a). O sociólogo e o TEN atuavam no sentido de aprofundar a identidade do negro como protagonista de uma transformação social necessária para a construção de um Brasil democrático e desenvolvido econômica, social e culturalmente.

Essa postura do níger sum antecipa em décadas a formulação do perspectivismo africano e do centro como localização que sustenta o paradigma da afrocentricidade (Asante, 2009, p. 96-97). Ademais, ao desafiar e inverter a relação pesquisador/objeto de pesquisa, se lançando ao estudo do "branco" e da brancura a partir do níger sum - seu lugar e sua perspectiva como negros - , eles anteciparam a teoria crítica racial (Delgado, 1997) e os estudos da branquitude (Bento, 2014; Cardoso; Schucman, 2014).

O Teatro Experimental do Negro exerceu um papel pioneiro ao engajar-se, enquanto entidade da sociedade civil, em ações e discussões de pesquisa e estudos, área então reservada à academia. Nesse particular, o TEN pode ser visto como precursor do Instituto Superior de Estudos Brasileiros, ISEB, outra instituição civil a se engajar na produção intelectual. Observa Guerreiro Ramos (1995, p. 205):

O TEN foi, no Brasil, o primeiro a denunciar a alienação da antropologia e da sociologia nacional, focalizando a gente de cor à luz do pitoresco ou do histórico puramente, como se se tratasse de elemento estático ou mumificado. Essa denúncia é o leitmotiv de todas as realizações do TEN, entre as quais o seu jornal Quilombo, a Conferencia Nacional do Negro (1949) e o I Congresso do Negro Brasileiro, realizado em 1950.

Afirma Abdias Nascimento (1950a, p. 1) que o TEN trabalha “[... ] aliando à face acadêmica do conclave o senso dinâmico e normativo que conduz a resultados práticos". Dessa forma, conclui ele (1950b, p. 1), o negro passa "[...] da condição de matéria-prima de estudiosos para a de modelador da sua própria conduta, do seu próprio destino". 
Tal postura não deixou de incomodar estudiosos que costumavam ver o negro como matéria prima ou objeto de pesquisa. Quando o TEN se posicionou publicamente sobre distorções a seu respeito presentes no trabalho do sociólogo Luiz Aguiar da Costa Pinto, este respondeu (Pinto, 1954, p. 2): “Duvido que haja biologista que depois de estudar, digamos, um micróbio, tenha visto esse micróbio tomar da pena e vir a público escrever sandices a respeito do estudo do qual ele participou como material de laboratório". A querela, bastante reveladora do quadro das relações raciais na época, compõe uma história fascinante que já tive oportunidade de relatar (Nascimento, E., 2003, p. 262-280; 350-368).

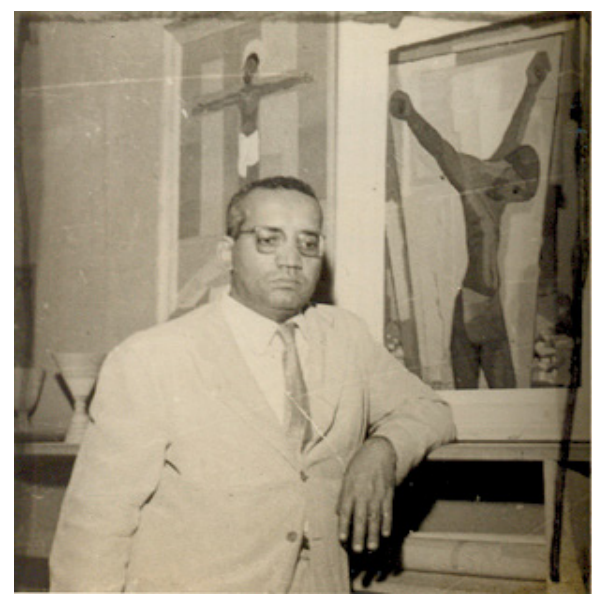

Foto 2: Guerreiro Ramos com obras do Concurso do Cristo de Cor organizado pelo Teatro Experimental do Negro. Rio de Janeiro, 1955 Fonte: IPEAFRO (1955)

\section{Sujeito Epistêmico: o Teatro Experimental do Negro (TEN) e o Cristo de Cor}

No ano seguinte, 1955, o Rio de Janeiro se preparava para receber delegações da Igreja Católica de todo o mundo no XXXVI Congresso Eucarístico Internacional. Em maio, o TEN realizava sua Semana de Estudos sobre Relações de Raça, cuja declaração de princípios reconhecia "[...] o recente incremento da importância dos povos de cor, politicamente independentes, como fatores ponderáveis na configuração 
das relações internacionais [...]" e conclama o Brasil a "[...] participar da liderança das forças internacionais interessadas na liquidação do colonialismo" (Guerreiro Ramos, 1995, p. 250-251).

O trabalho do TEN já vinha unindo a estética à atuação política. Além das apresentações teatrais, realizava concursos de beleza para mulheres negras como instrumento pedagógico e "terapêutica de desrecalcamento em massa", pois

[...] as classes ditas superiores mantinham o nosso povo obnubilado pelos padrões estéticos alienados e alienantes da brancura, esta constituindo uma ideologia corruptora e perversa, ao negar a beleza negra no contexto vivo da estética brasileira. (Nascimento, A., 1968b, p. 41)

No I Congresso do Negro Brasileiro, em 1950, houve acalorada discussão da necessidade de se criar um museu de arte negra.

Em outubro de 1954, sai na revista Forma o artigo "O negro desde dentro", de Guerreiro Ramos (1995, p. 241-248), em que o autor afirma que a beleza negra

[…] não é, porventura, criação cerebrina dos que as ciruncstâncias vestiram de pele escura, espécie de racionalização ou justificação, mas um valor eterno, que vale ainda que não seja descoberto. Não é uma reivindicação racial o que confere positividade à negrura: é uma verificação objetiva. É assim, objetivamente, que pedimos para a beleza negra o seu lugar no plano egrégio. (Guerreiro Ramos, 1995, p. 244)

Essa afirmação resume uma dimensão importante do discurso e ação da luta anticolonialista pan-africana protagonizada por poetas como Aimé Césaire e Léopold Sédar Senghor, de cujos textos Guerreiro transcreve trechos. O TEN se mantinha ligado e solidário à luta independentista e ao movimento da Negritude, presente nas páginas do seu jornal Quilombo.

A realização do Congresso Eucarístico Mundial no Rio de Janeiro apresentou-se a Guerreiro Ramos e aos artistas e intelectuais do TEN como uma oportunidade sem igual para a afirmação dessa estética: propuseram e realizaram, em parceria com a Revista Forma um concurso de pintura sobre o tema do Cristo Negro. Com apoio de artistas 
e intelectuais como Quirino Campofiorito, Dinah Silveira de Queiroz e Augusto Frederico Schmidt, além do então arcebispo auxiliar Dom Helder Câmara, a iniciativa foi motivo de grande polêmica na imprensa (IPEAFRO, 1955). “Está prestes a ser aberta ao público uma exposição de pintura que reúne em si a blasfêmia e o sacrilégio, aliados ao mau gosto", dizia uma crítica no Jornal do Brasil (Uruguay, 1955):

É a do Cristo Negro. [...] Essa exposição que se anuncia deveria ser proibida como altamente subversiva. Tal acontecimento realizado às vésperas do Congresso Eucarístico, foi preparado adrede para servir de pedra de escândalo e motivo de repulsa. O nosso descontrole moral, a nossa grande falta de respeito e de bom gosto, o nosso triste estado d'alma, não podem ser dados em espetáculo aos que nos visitam. Damos aqui o brado de alarma. As autoridades eclesiásticas devem, quanto antes, tomar providências para impedir a realização desse atentado feito à Religião e às Artes.

Outras matérias e reportagens, quase sem exceção, levantam a questão do racismo às avessas.

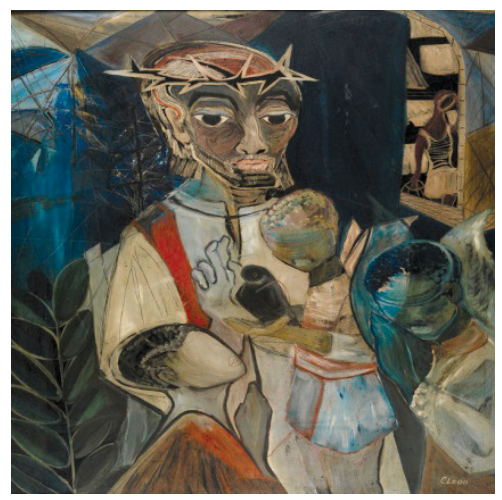

Foto 4: Cléoo, Cristo Negro. Óleo sobre madeira, 76 x 112 cm. Rio de Janeiro, 1955 Fonte: IPEAFRO (1955)

Na Tribuna da Imprensa, a legenda que acompanha a imagem do quadro da pintora negra Cleoo Novarro afirma: "Eis como Cleo Novarro concebe um Cristo de cor. Não é racismo, é homenagem ao Congresso Eucarístico". O texto esclarece: "Ao contrário do que muita gente pensou (e ainda pensa), explicam-nos os organizadores da mostra que o objetivo pretendido não foi testemunhar um incipiente racismo 
do negro brasileiro" (Se Cristo fosse preto, 1955). Outra matéria traz como subtítulos "Continuará a Polêmica Em Torno das Pinturas do Concurso Forma - Teatro Experimental do Negro" e "Não se estará criando um racismo 'Às avessas'?" (Bastos, 1955, p. 5). Abdias Nascimento responde nesta mesma reportagem:

Na contemplação da beleza negra, nesta exaltação explícita e subjacente dos valores negros, a negrura não é anti-branca, não é agressiva e nem separatista. Ao contrário, pacífica e integrativa, ela oferece o que de mais universal, de mais ecumênico, e, pois, de mais excelso e católico existe na sua substância negra como é exemplo, feliz e atual, o concurso do "Cristo de Côr", idealizado pelo sociólogo Guerreiro Ramos e promovido conjuntamente pelo T. E. N. e pela revista "Forma".

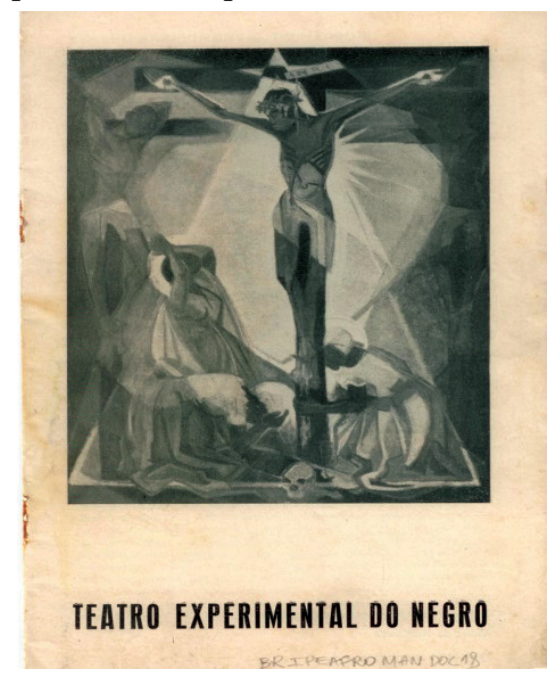

Foto 3: Capa do programa do Concurso Cristo de Cor e da peça $O$ filho pródigo. Teatro Experimental do Negro, 1955 Fonte: IPEAFRO (1955)

Quirino Campofiorito (1966, p. 143) comenta o sucesso do concurso:

[...] encerrada a inscrição, e às vesperas do julgamento, verificamos que o sucesso ultrapassou mesmo a expectativa mais otimista daqueles que já nos garantiam uma concorrência apreciável. Bem oitenta trabalhos de pintura, em técnicas e sentidos estéticos os mais diversos, 
darão uma ótima impressão da arte interessada num tema palpitante, que é a concepção do Cristo de côr. Palpitante, audaciosa e mesmo temerária, dado que não será fácil vencer a convicção sôbre o Messias branco.

Desse conjunto, foram selecionadas 52 quadros, expostos no salão do Ministério da Educação (Palácio Gustavo Capanema) de 17 a 24 de julho, listados por autor no catálogo ao lado de informações sobre a apresentação pelo TEN da peça $O$ filho pródigo, de Lúcio Cardoso, no Teatro Carlos Gomes nos dias 18 a 25 de julho (Nascimento, A., 1955, p. 10-11). Dom Helder Câmara, Secretário Geral do $36^{\circ}$ Congresso Eucarístico Internacional, assina o texto de contracapa do catálogo apresentando o concurso e a peça teatral ao público e afirmando que o TEN, “[...] uma das maiores realizações do teatro brasileiro, é a mais feliz das afirmações das possibilidades do negro no campo da cultura".

Vencedora do concurso, a artista Djanira criou um "Cristo na coluna", mostrando o martírio de um Jesus escravizado no Pelourinho de Salvador (Nascimento, A., 1955, p. 7), semelhante à de Otávio Araújo, pintor negro que concebeu um "Cristo na favela"

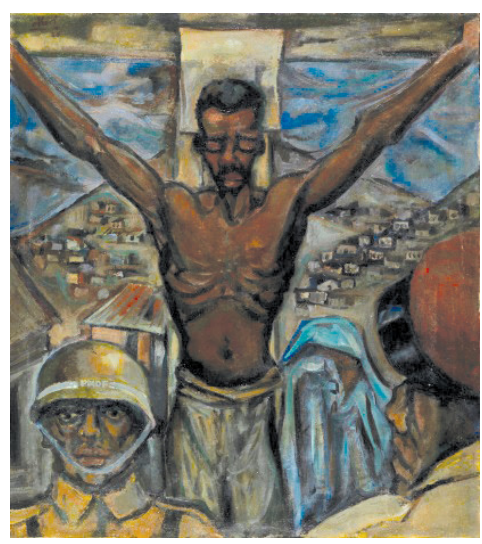

Foto 5: Otávio Araújo, Cristo Favelado. Óleo sobre tela, 53 x 64 cm. Rio de Janeiro, 1955

Fonte: IPEAFRO (1955)

Essa ideia orientou também o segundo colocado, Marques de Sá, e outros artistas, sendo bem recebida pela crítica (Bastos, 1955, p. 5): 
Colocaram Cristo nos dias atuais, crucificado ou flagelado em bairros pobres, entre mulheres do povo, famintas e sofredoras. Essa concepção realista mereceu a aprovação da maioria do júri e foi realmente a nota mais autêntica da exposição. O Cristo negro seria, pois, um homem contemporâneo, explorado e sofredor.

O teor didático da iniciativa expressou-o o seu idealizador, Guerreiro Ramos (1955, p. 2,4), ao relatá-la, em texto bem didático, como "consequência de um incidente familiar":

De fato, por ocasião das festas natalinas do ano passado, minha filha de cinco anos, que se educa em colégio católico, entre outras cantigas, aprendeu uma em que havia estes versos:

"Cabelos loiros

Olhos azuis

És meu tesouro

Nosso Jesus"

Ouvindo-a cantar reiteradamente estes versos fui levado a refletir que debaixo daquela manifestação natalina havia uma insinuação preconceituosa. E minha convicção foi reforçada ao testemunhar o espanto da criança quando lhe disse que nosso Senhor Jesus Cristo, em sua vida terrena, não fora louro, nem tivera olhos azuis. Ao contrário, fora provavelmente um homem trigueiro, de tonalidade muito próxima da do mulato brasileiro. [...] A nossa corrente idealização de Nosso Senhor, como homem louro e de olhos azuis, reflete uma alienação estética, um autodesprezo, uma atitude de subserviência, na qual renunciamos a um critério comunitário e imediato do belo e do excelso em favor de um critério estranho à vida nacional. Jesus Cristo, em sua representação natural no Brasil, não poderia nunca ser louro e nem de olhos azuis, se desejamos ser autênticos.

A fundamentação histórica da identidade "trigueira" de Jesus Cristo não figura como enfoque principal dos organizadores, mas está presente nos textos (Nascimento, A., 1955, p. 6, 8; Ramos, 1955, p. 2, 4).

No seu conjunto, a iniciativa do Concurso do Cristo de Cor complementado pela apresentação da peça teatral $O$ filho pródigo se caracteriza como um belo exemplo da ação do "sujeito epistêmico" 
idealizado por Guerreiro Ramos em sua juventude (Antelo, 2015, p. 5) e caracterizado por Agnes Heller (1982, p. 137) como transformador de carecimento como ausência em carecimento como projeto. Já o sociólogo Manuel Castells (1999, p. 24-26) tipifica as identidades de resistência e projeto, conceitos que dialogam com os de Heller e Guerreiro e Ramos. Em sua concepção, a identidade de projeto entra em cena quando os atores sociais criam uma nova identidade capaz de reformular sua inserção na sociedade. Assim, a identidade de projeto produz sujeitos - indivíduos e atores sociais coletivos - que procuram transformar a estrutura social. É exatamente essa a proposta de Guerreiro Ramos e do TEN com o conjunto de suas iniciativas. "Reivindicar uma identidade", diz Castells (1999, p. 235), "é construir poder". Entretanto, esse autor (Castells, 1999, p. 79) minimiza a identidade racial ou étnica como fator importante: "dificilmente se pode dizer que seja ainda capaz de construir significados". Neste particular, ele difere dos intelectuais do TEN e também de Agnes Heller, para quem "todos os estratos sociais que expressam carecimentos radicais podem tornar-se sujeitos da transformação revolucionária" (Heller, 1982, p. 133). Em minha opinião, o Teatro Experimental desempenhou esse papel, tendo continuidade nos movimentos negros que o sucederam. Construíram significados em diversos fronts, resultando, a partir do limiar do século XXI, na implantação de políticas de ação afirmativa na cultura, na educação, no mercado de trabalho e na sociedade civil cujos efeitos a sociedade ainda sente hoje. Em nível internacional, o TEN se enquadra no conjunto de atores sociais e intelectuais que conquistaram a independência dos países colonizados e protagonizaram mudanças importantes na academia, na produção intelectual e nas sociedades civis, construindo os novos paradigmas do mundo pós-moderno.

\section{Orixás e Estética Epistêmica}

O Concurso do Cristo de Cor integra o contexto das iniciativas do TEN unindo estética e política, que teriam maior expressão no projeto Museu de Arte Negra (MAN) idealizado no I Congresso do Negro Brasileiro. Em 1968, Abdias Nascimento abre a exposição inaugural do MAN no Museu da Imagem e do Som. Logo em seguida, ele 
segue para os Estados Unidos, de onde é impedido de voltar, alvo da repressão intensificada pelo Ato Institucional n. 5. Sua participação nos movimentos da Arte Negra e do Poder Negro e seu diálogo com organizações e intelectuais negros na África, no Caribe e nos Estados Unidos são fatos pouco conhecidos que tive a oportunidade de registrar na biografia que escrevi a pedido do Senado Federal (Nascimento, E., 2014, p. 197-234).

Durante sua jornada no exterior, Abdias desenvolveu a pintura que havia iniciado antes de sair do Brasil, incentivado pela convivência com o pintor Sebastião Januário. À exposição "Os Orixás", mencionada no início deste ensaio, seguiram-se dezenas mais. Guerreiro Ramos, cujo trabalho na Universidade da Califórnia do Sul (USC) voltava-se para a administração pública, se afastando, aparentemente, do enfoque sobre estética e negritude, acompanhava e não se furtava a testemunhar a trajetória de Abdias. Dessa forma, Guerreiro deu continuidade a seu engajamento com a questão racial.

Bem no seu estilo de leveza incisiva, escrevendo em inglês, Guerreiro Ramos (1971, p. 2) observa que, na sociedade contemporânea,

O melhor do nosso ser fica reprimido enquanto somos coagidos a sermos criaturas capazes de enfrentar as vicissitudes de nossa vida cotidiana. No atual mundo fragmentado, vivemos sob a lei marcial, compelidos a dividir-nos em papeis separados e constrangedores. Essa condição humana nos faz voltar para latentes realidades tonificantes. Presos à moldura convencional da vida em sociedade, normalmente estamos pervertidos.

Diante dessa situação, “[...] os quadros de Abdias do Nascimento implicam nada menos que numa revolução! Falam-nos sobre a integridade, unidade e autorrealização humanas".

Há nas telas, de acordo com Guerreiro Ramos (1974, p. 3), “[...] um sentido restaurativo relativo ao significado contemporâneo da cultura negra no Brasil e em todo lugar". Veem-se os símbolos religiosos africanos numa perspectiva evolucionista, como se hoje fossem arcaicos ou primitivos. Abdias confronta essa premissa, mostrando que os símbolos religiosos "[...] podem diferir no tempo e no espaço, mas a experiência humana que eles exprimem é basicamente a mesma. 
Assim, a verdade dos símbolos religiosos africanos não é menos válida que aquela dos símbolos religiosos ocidentais." (Guerreiro Ramos, 1974, p. 3).

"Atores intrigantes" das telas, os orixás nos contam que a água, o céu e a terra "são feitos do mesmo nada, que é o divino". Guerreiro Ramos (1974, p. 3) afirma que esse aspecto da arte de Abdias tem um significado profundo: "todas as coisas e criaturas haverão de se unir". As telas nos conduzem a um mundo tribal onde "[...] a natureza fala às mulheres, homens e deuses, e eles respondem" (Guerreiro Ramos, 1995a, p. 95). Esse tribalismo, longe de representar uma volta ao passado congelado, enriquece a experiência contemporânea. “Sua visão é tribal, não por ser exclusivista e segregacionista, mas por ser inclusiva e compatível com as propensidades do homem global de Marshall McLuhan - um verdadeiro cidadão deste mundo nosso." (Guerreiro Ramos, 1995a, p. 95).

A arte de Abdias se impõe como "característica autêntica da revolução negra de hoje", diz Guerreiro Ramos (1995a, p. 95, 97). "Como negro, ele se identifica com todos os esforços de libertação desatados por aqueles prejudicados pela escuridão de sua pele".

A alienação ainda pesa muito como carga da condição humana em toda a parte. Entretanto, o negro se encontra peculiarmente alienado em comparação a outros indivíduos. Essa peculiaridade é o que a arte de Abdias tenta exprimir, embora não se limite somente a isto. Ele traz os motivos e temas negros para a corrente principal dos ideais humanistas do século vinte. Tais ideais são certamente factíveis, mas não inevitáveis, e beneficiariam toda a humanidade independentemente da cor. O mundo atual, no rumo em que está, se dirige a um final terrível e trágico. Não realizaremos suas possibilidades positivas e esperançosas sem as lutas e os empenhos que a vida de Abdias testemunha. (Guerreiro Ramos, 1995a, p. 95, 97) 


\section{Conclusão}

A vida e obra de Guerreiro Ramos nos instigam a reflexões em diversos campos de atuação e investigação. Neste pequeno ensaio, tentei focalizar o alcance mais amplo de seu trabalho pioneiro com a questão racial, que dialoga com paradigmas sociológicos, tendências e debates intelectuais, movimentos sociais e a evolução da sociedade civil no mundo. Sua conceituação do "sujeito epistêmico" emerge como caracterização de sua própria vivência da questão racial e da militância sociológica no interior do Teatro Experimental do Negro. A convivência com Abdias Nascimento, numa amizade tecida num caminho de construção conjunta de ação e pensamento, dificilmente se separa da trajetória intelectual de Guerreiro. Aliás, em entrevista concedida à Revista Marco (n. 4, 1954), ele declarou (Guerreiro Ramos, 1995, p. 267) que um de seus "mais amoráveis projetos para quando dispuser de mais tempo" era escrever "a história secreta de Abdias Nascimento". Certamente, ele se aproximou à concretização desse desejo com os testemunhos que deixou nos catálogos das exposições do amigo em diversas instituições culturais. Em minha opinião, esses textos estão à altura do gênio de Guerreiro Ramos em todos os campos em que agiu.

\section{Agradecimentos}

Agradeço o convite do Núcleo de Estudos de Identidade e Relações Interétnicas (NUER) da Universidade Federal de Santa Catarina, para participar do Seminário "Guerreiro Ramos, intérprete do Brasil", que me propiciou a oportunidade de conviver e interagir com um conjunto diverso e fascinante de estudiosos da obra do homenageado, e que promove a publicação desta coletânea.

\section{Notas}

1 M.A. J. D., Universidade do Estado de Nova York, EUA; Ph.D., Universidade de São Paulo. Diretora, Instituto de Pesquisas e Estudos Afro-Brasileiros (IPEAFRO), rua Benjamin Constant, 55/1101, Rio de Janeiro, RJ, 20241-150. 


\section{Referências}

ANTELO, Raul. Ensaios críticos, vanguarda e intelectualidade. Guerreiro Ramos, o não-contemporizador. Conferência de abertura. In: SEMINÁRIO “GUERREIRO RAMOS, INTÉRPRETE DO BRASIL". Núcleo de Estudos de Identidades e Relações Interétnicas (NUER), Universidade Federal de Santa Catarina, 11 de setembro de 2015. Anais... UFSC, Santa Catarina, 2015.

ASANTE, Molefi Kete. Afrocentricidade: notas sobre uma posição disciplinar. In: NASCIMENTO, Elisa Larkin. (Org.). Afrocentricidade, uma abordagem epistemologica inovadora. São Paulo: Selo Negro, 2009.

BASTOS, Clemente de Magalhães. Cristo de Cor, Ideia que Suscitou Debates Artísticos e Sociológicos. Diário de Notícias, [S.l.], Suplemento Literário. 31 jul. 1955, p. 5. Disponível em: < http://ipeafro.org.br/acervodigital/documentos/man-documentos/cristo-de-cor-2/>. Acesso em: 2 jun. 2016.

BENTO, Maria Aparecida da Silva. Branqueamento e branquitude no Brasil, 2014. Racismo Institucional, [S.l.], UFMG: Fórum de debates educação e saúde. Disponível em: < http://www.cehmob.org.br/wp-content/ uploads/2014/08/Caderno-Racismo.pdf\#page=5>. Acesso em: 9 mar. 2016.

BRIGAGÃO, Clóvis. Da sociologia em mangas de camisa à túnica inconsútil do saber. In: RAMOS, Alberto Guerreiro. Introdução crítica à sociologia brasileira. 2. ed. Rio de Janeiro: Editora da Universidade Federal do Rio de Janeiro, 1995. p. 9-18.

CARDOSO, Lourenço; SCHUCMAN, Lia Vainer. (Org.). Dossiê Branquitude. Revista da ABPN, [S.l.], v. 6, n. 13, mar.-jun. 2014.

CAMPOFIORITO, Quirino. Cristo de cor. In: NASCIMENTO, Abdias. (Org.). TEN: Testemunhos. Rio de Janeiro: GRD, 1966. p. 143-145. [O Jornal, 26 jun. 1955]

CASTELLS, Manuel. O poder da identidade: a era da informação economia, sociedade e cultura. São Paulo: Paz e Terra, 1999. v. 2.

CÉSAIRE, Aimé. Discours sur le colonialism. Paris: Présence Africaine, 1955.

DELGADO, Richard (Org.). Critical race theory. Filadélfia: Temple University Press, 1997.

DIOP, Cheikh Anta. Nations négres et culture. Paris: Présence Africaine, 1955. 
DIOP, Cheikh Anta. Anteriorité des civilizations négres: mythe ou verité historique? Paris: Présence Africaine, 1959.

DU BOIS, William Edward Burghardt. Writings: The suppression of the African slave-trade, The souls of black folk, Dusk of dawn, essays and articles, org. Nathan Huggins. Nova York: The Library of America, 1986. $1.334 \mathrm{p}$.

GUERREIRO RAMOS, Alberto. Não. A Ordem, [s.l.], v. 17, n. 81, 1937.

GUERREIRO RAMOS, Alberto. Teoria e prática do psicodrama. Quilombo: Problemas e aspirações do negro brasileiro, [S.l.], v. 2, n. 6, p. 6-7, fev. 1950a.

GUERREIRO RAMOS, Alberto. Teoria e prática do sócio-drama (notas). Quilombo: Problemas e aspirações do negro brasileiro, [S.l.], v. 2, n. 7/8, p. 9, mar.-abr. 1950b.

GUERREIRO RAMOS, Alberto. Nosso senhor Jesus Cristo trigueiro. Diário de Notícias, [S.l.], p. 2, 4, 10 de abril de 1955. Disponível em: <http:// ipeafro.org.br/acervo-digital/documentos/man-documentos/cristo-decor-2/>. Acesso em: 2 jun. 2016.

GUERREIRO RAMOS, Alberto. Abdias do Nascimento's tribal world. In: NASCIMENTO, Abdias do. A Brazilian Brother. Catálogo de exposição. Dorchester, MA, EUA: Museum of the National Center of Afro-American Artists, 1971. Disponível em: < http://ipeafro.org.br/acervo-digital/ documentos/man-exposicoes-de-abdias/museum-of-national/>. Acesso em: 2 jun. 2016.

GUERREIRO RAMOS, Alberto. Nascimento's Artistic Faith. In:

NASCIMENTO, Abdias. Catálogo de exposição. Langston Hughes Center for the Visual and Performing Arts, Buffalo, NY, EUA, 21 April - 12 May 1974, p. 2, 3 e 8. Tradução de Elisa Larkin Nascimento. Disponível em: $<$ http://ipeafro.org.br/acervo-digital/documentos/man-exposicoes-deabdias/langston-hughes/> . Acesso em: 2 jun. 2016.

GUERREIRO RAMOS, Alberto. Introdução crítica à sociologia brasileira. 2. ed. Rio de Janeiro: Editora da Universidade Federal do Rio de Janeiro, 1995.

GUERREIRO RAMOS, Alberto. A redução sociológica. 2. ed. Rio de Janeiro: Editora da Universidade Federal do Rio de Janeiro, 1996.

FANON, Frantz. Pele negra, máscara branca. Salvador: Fator, 1983.

HELLER, Agnes. Para mudar a vida: Felicidade, liberdade e democracia. Entrevista a Ferdinando Adornato. São Paulo: Brasiliense, 1982.

HELLER, Agnes. Everyday life. Londres: Routledge Kegan \& Paul, 1987. 
HELLER, Agnes. From Hermeneutics in Social Science toward a Hermeneutics of Social Science. Theory and Society, [S.l.], v. 18, n. 3, 1989, p. 291-322.

IPEAFRO. Acervo Instituto de Pesquisas e Estudos Afro-Brasileiros. Seção Museu de Arte Negra, Série Documentos do MAN, 1955. Disponível em: <http://ipeafro.org.br/acervo-digital/documentos/man-documentos/ cristo-de-cor-1/>. Acesso em: 2 jun. 2016.

IPEAFRO. Acervo Instituto de Pesquisas e Estudos Afro-Brasileiros. Seção Biografia e Produção Intelectual de Abdias Nascimento, Dossiê Diplomas e Honrarias, item 6. (Diploma Pós-Universitário expedido pelo Instituto Superior de Estudos Brasileiros (ISEB) em 20 de dezembro de 1956. Disponível em: < http://ipeafro.org.br/acervo-digital/documentos/babiografia/diplomas-e-honrarias $>$. Acesso em: 2 jun. 2016.

MEMMI, Albert. The colonizer and the colonized. Trad. Howard Greenfield. Boston: Beacon Press, 1967.

NASCIMENTO, Abdias. (Org.). Dramas para negros e prólogo para brancos. Rio de Janeiro: Teatro Experimental do Negro, 1961.

NASCIMENTO, Abdias. (Org.). O negro revoltado. Rio de Janeiro: GRD, 1968 .

NASCIMENTO, Abdias. (Org.). Teatro Experimental do Negro.

Catálogo da exposição do concurso Cristo de Cor e da apresentação da peça "O filho pródigo", de Lúcio Cardoso. Rio de Janeiro: Teatro Experimental do Negro, 1955a.

NASCIMENTO, Abdias. (Org.). TEN: testemunhos. Rio de Janeiro: GRD, 1966.

NASCIMENTO, Abdias. $1^{\circ}$ Congresso do Negro Brasileiro. Editorial. Quilombo, [S.l.], v. 2 n. 5, p. 1, jan. 1950a.

NASCIMENTO, Abdias. A arte negra - Museu voltado para o futuro.

Revista Galeria de Arte Moderna, [S.l.], n. 15, p. 41, 44, 1968 b.

NASCIMENTO, Abdias. Inaugurando o Congresso do Negro. Editorial. Quilombo, [S.l.], v. 2, n. 10, p. 1, jun.-jul. 1950b.

NASCIMENTO, Abdias. O quilombismo. 2. ed. Brasília, DF: Fundação Palmares, 2002.

NASCIMENTO, Abdias. Orixás: os Deuses Vivos da África/Orishas: the Living Gods of Africa in Brazil. Tradução e coorganização de Elisa Larkin Nascimento. Rio de Janeiro: IPEAFRO, 1995b. p. 93-97. 
NASCIMENTO, Abdias. The Orixás. Middletown, EUA: Center for the Humanities, Wesleyan University, 1969. Disponível em: <http://ipeafro. org.br/acervo-digital/documentos/man-exposicoes-de-abdias/malcolm-xhouse/>. Acesso em: 2 jun. 2016.

NASCIMENTO, Elisa Larkin. Abdias Nascimento. Coleção Grandes Vultos que Honraram o Senado. Brasília, DF: Senado Federal, 2014.

NASCIMENTO, Elisa Larkin. O sortilégio da cor: identidade, raça e gênero no Brasil. São Paulo: Selo Negro, 2003.

PINTO, L. A. da Costa. Ciência social e ideologia racial - Esclarecendo intencionais obscuridades. O Jornal, Rio de Janeiro, p. 2, 10 jul. 1954.

SE CRISTO FOSSE PRETO. Tribuna da Imprensa, [S.l.], 22 de julho de 1955. Acervo IPEAFRO. Disponível em: <http://ipeafro.org.br/acervodigital/documentos/man-documentos/cristo-de-cor-2/>. Acesso em: 2 jun. 2016.

URUGUAY, Alice Linhares. Cristo negro. Seção Artes Plásticas, Jornal do Brasil, [S.l.], 26 de junho de 1955. Disponível em: < http://ipeafro.org.br/ acervo-digital/documentos/man-documentos/cristo-de-cor-2/>. Acesso em: 2 jun. 2016.

Recebido em 15/04/2016

Aceito em 19/04/2016 